\title{
Case report of a medication error by look-alike packaging: a classic surrogate marker of an unsafe system
}

\author{
Joerg Schnoor ${ }^{1 *}$, Christina Rogalski ${ }^{2}$, Roberto Frontini ${ }^{5}$, Nils Engelmann ${ }^{3,4}$ and Christoph-Eckhardt Heyde ${ }^{6}$
}

\begin{abstract}
Background: The acronym LASA (look-alike sound-alike) denotes the problem of confusing similar- looking and/or sounding drugs accidentally. The most common causes of medication error jeopardizing patient safety are LASA as well as high workload.

Case presentation: A critical incident report of medication errors of opioids for postoperative analgesia by lookalike packaging highlights the LASA aspects in everyday scenarios. A change to a generic brand of medication saved costs of up to $16 \%$ per annum. Consequently, confusion of medication incidents occurred due to the similar appearance of the newly introduced generic opioid. Due to consecutive underdosing no life-threatening situation arose out of this LASA based medication error.

Conclusions: Current recommendations for the prevention of LASA are quite extensive; still, in a system with a lump sum payment per case not all of these security measures may be feasible. This issue remains to be approached on an individual basis, taking into consideration local set ups as well as financial issues.
\end{abstract}

Keywords: Patient safety, Look alike-sound alike, LASA, Medication error, Costs, High work load

\section{Background}

In a health care system based on lump sum payment (Diagnosis-Related Group, DRG), competing suppliers of health care are forced to optimize cost efficiency to generate revenue. Simultaneously, patient safety has become an overall goal for all parties involved, and can limit cost efficiency and hence revenue substantially.

Patient safety is at risk due to medication errors, and roughly $30 \%$ are due to similar packaging and labeling, as well as illegible handwriting. The term LASA ("lookalike sound-alike") delineates a confusion of medication due to the similar labeling and packaging of different drugs, or similar labeling and packaging of the same drug containing different strengths.

These errors occur along the line of prescribing, preparing, distributing and administering medication. Various factors contribute to the LASA incident, and accounts for $7-20 \%$ of all medication errors [1-5]:

\footnotetext{
* Correspondence: Joerg.Schnoor@medizin.uni-leipzig.de

'Department of Anesthesia and Intensive Care Medicine, University Hospital Leipzig, Liebigstraße 20, 04103 Leipzig, Germany

Full list of author information is available at the end of the article
}

- illegible handwriting

- oral and vague prescription ("half an ampule")

- incomplete knowledge of name of medication and substance

- newly released drugs in ever shorter periods of time

- similar packaging and labeling

- dismissing barcode technology at point of care

- similar clinical use of drugs

- similar dosage and concentration

- diverging concentration on similarly looking packaging

- displaying concentration in percent instead of numerical units

- dismissing the use of capital letters (ie. PENTObarbital versus PHENObarbital)

- confusing and/or no separate stocking of high risk medication

A typical case of LASA has been published recently [6].

To demonstrate the reciprocity of patient safety and cost efficiency, this true report of medication errors highlighted by the use of a Critical Incident Reporting 
System (CIRS) is utilized. Savings on changing to a generic brand are calculated and measures to avoid medication errors are demonstrated, as published by most recent guidelines.

\section{Case presentation}

Upon restocking opioids, changing from Dipidolor ${ }^{\mathrm{Tx}}$ (a trade name of Piritramid from the Janssen-Cilag $\mathrm{GmbH}$, Germany) to the generic brand Piritramid (Hameln pharma, Germany), with Dipidolor being a commonly used opioid for post-operative pain in Germany, opioids were ordered as a $1 \mathrm{ml}$ vial containing $7.5 \mathrm{mg} / \mathrm{ml}$ of Piritramid, instead of the usually ordered and used $2 \mathrm{ml}$ vials containing $15 \mathrm{mg} / 2 \mathrm{ml}$ of Piritramid, still from the same manufacturer (see the figure of medication boxes (Figure 1)). However, these stocks were falsely registered as $2 \mathrm{ml}$ vials in the drug cupboard logbook on the ward. In some cases, prescriptions were made as "... administer half a vial of Piritramid..." by physicians. A CIRS was filed anonymously, however, at this point no conclusion could be drawn as how many patients had been involved and which patient had received what dosage. Assumingly "half an vial" of Piritramid has led to some patients receiving $3.75 \mathrm{mg}$ of Piritramid instead of $7.5 \mathrm{mg}$.

As a learning system, the in-house CIRS is operating since 2010 on an electronic basis, voluntarily and anonymously. All cases are electronically published and archived. Two days after this case had been reported, both a review on anonymity and a request for proposals to the departments that may be involved were conducted. Two weeks later, the incoming suggestions on practicality were reviewed and, if possible, implemented.

\section{What recommendations have been published?}

Apart from the regular requirements for staff, like holding a recognized degree in medicine or nursing, maximum attention to be paid when making difficult decisions on or distribution of any medication, or a sufficient number of staff to shoulder the workload, there are numerous recommendations [1]:

- interdisciplinary cooperation (pharmacist, physicians, auxiliary staff, commission on medication) regarding stocks of medication available

- non-standardized medication should be prepared by in-house pharmacy. Whenever feasible, ready to use/ ready to administer drugs should be given

- replacing similar sounding drugs by drugs with different brand name containing same substance maintain awareness for LASA issue. Keeping lists of such drugs, which can enhance awareness for the potential of medication error. Regular updates from the in-house CIRS should be mandatory

- if LASA prone medication is in use, these drugs should be highlighted by pharmacy or relabeled altogether (signal effect for potential danger of medication error)

- barcode scanning technology to be implemented at point of care

- all members of staff involved in medicating patients should receive recurring training for awareness of LASA

- stringent feedback of LASA issues to FDA and pharmaceutical industry via pharmacists from hospitals

A proven concept is the double verification principle or two-man rule. In Addition, there are various recommendations on logistics to reduce medication errors as well [7]:

- considering LASA when ordering stocks. Whenever feasible, preferring alternative suppliers

- ideally, only one strength/concentration of each substance should be available on wards. Diverging

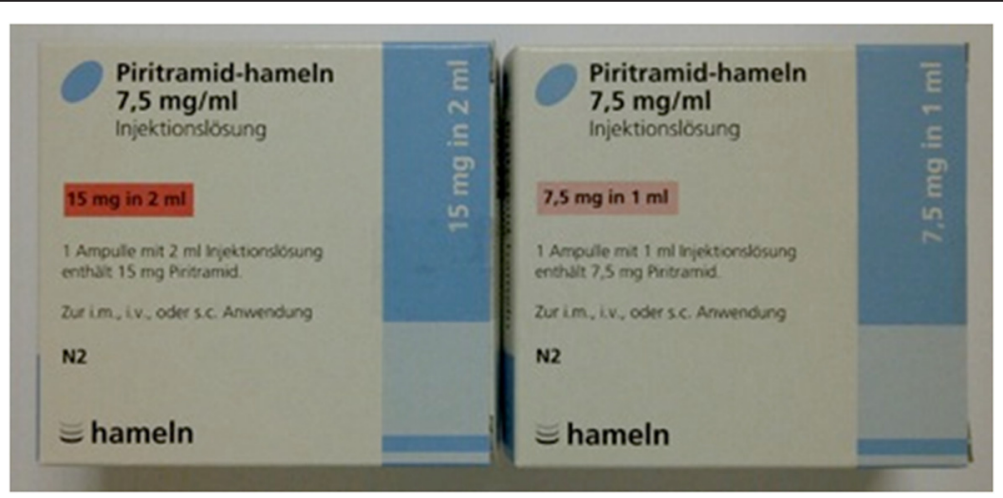

Figure 1 Medication boxes of Piritramid-hameln (Hameln, Germany) with $2 \times 5$ vials ad 2 ml-vials (15 mg Piritramid) and 1 ml-vials (7,5 mg Piritramid), respectively. 
concentrations should be ordered according to individual cases only

- if, however, LASA medication needs to be stocked, these should carry warning labels, especially high risk medication with a narrow therapeutical margin, for example cardiovascular drugs, anesthetic drugs, cytostatins, high risk electrolyte carrying fluids, and the likes. Separate stocking of such drugs

- a change to a barcode driven medication process can reduce the risk of confusing drugs significantly $[7,8]$

\section{Previous changes in medication}

Prior to this incident, a change was proposed from staff regarding usage of Piritramid $2 \mathrm{ml}$ vials, as

- half of the substance ( $15 \mathrm{mg}$ vials of $2 \mathrm{ml}$ of Piritramid) was mostly discarded.

- cost efficiency could be achieved by switching to a generic product.

\section{Impact of change to a generic substance}

The change to the generic Piritramid was implemented on June $6^{\text {th }}$ 2011. A pharmacy audit of 2010-2012 showed a reduction in prescribed Piritramid distribution (see the figure of pharmacy dispensing of Dipidolor ${ }^{\mathrm{TM}}$ - and Piritramid-vials (Figure 2)). However, a multi-nodal pain bundle was implemented around that time as well, including an increase in regional anesthesia techniques intra-operatively, and could contribute to this downturn in post-operative opioid consumption of Piritramid considerably. Additionally, incomplete knowledge of newly introduced drugs and dosages could be adding to this phenomenon.

Whether long-term effects based on an ageing population with a decreased need for opioids, or shorter overall stays in our hospital were attributing to this remains debatable, as pharmacy audit of 2012 showed a balanced consumption (see the figure of pharmacy dispensing of Piritramid-packs per month in 2012 (Figure 3)) again.

\section{Costs}

A change in brands of stocked medication creates costs. Analysis of this process conducted by a University demonstrated costs of US\$ 2.400 for a simple change to a generic substance.

A change to a generic substance with a different brand name amounted to US\$ 5.200 on average. Introducing a different substance and name to replace a brand came with a price tag of around US\$ 6.480 [9]. These costs are of course examples, whether these can be assigned to other changeovers remains to be seen.

Table 1 demonstrates a gross cost ratio of our given case (German prices). The observed pool of costs relating to Piritramid showed a reduction of $50 \%$ over the course of a three years' time. During these three years of
Table 1 Drug costs observed (List price 2012 in EURO; 1 Euro 1,38 USD [10])

\begin{tabular}{llll}
\hline $\begin{array}{l}\text { Drugs } \\
\text { (number of vials per } \\
\text { package and costs) }\end{array}$ & $\mathbf{2 0 1 0}$ & $\mathbf{2 0 1 1}$ & $\mathbf{2 0 1 2}$ \\
\hline $\begin{array}{l}\text { Dipidolor }{ }^{\mathrm{TM}} 15 \mathrm{mg} / 2 \mathrm{ml} \\
(5 \text { vials } 17,17 €)\end{array}$ & $\mathrm{n}=42.400$ & $\mathrm{n}=17.500$ & $\mathrm{n}=0$ \\
Piritramid $15 \mathrm{mg} / 2 \mathrm{ml}$ & $\mathrm{n}=0$ & $\mathrm{n}=18.300$ & $\mathrm{n}=26.400$ \\
$(10$ vials $21,97 €)$ & & $40.205,10 €$ & $58000,80 €$ \\
Piritramid 7,5 mg/1 $\mathrm{ml}$ & $\mathrm{n}=0$ & $\mathrm{n}=4.500$ & $\mathrm{n}=8.000$ \\
$(10$ vials $18,40 €)$ & & $8280,00 €$ & $14.720,00 €$ \\
Total costs (EURO) & $145.601,60$ & $108.580,10$ & $72.720,80$ \\
Total costs (USD) & $\mathbf{2 0 0 . 9 3 0 , 2 1}$ & $\mathbf{1 4 9 . 8 4 0 , 5 4}$ & $\mathbf{1 0 0 . 3 5 4 , 7 0}$ \\
\hline
\end{tabular}

observation we found a decline in distribution of Piritramid of $19 \%$. The change to a generic brand alone generated a cost reduction of $16 \%$ per year. This reduction in costs needs to be put in contrast to errors occurring in medicating patients with Piritramid $7.5 \mathrm{mg}$ vials and Piritramid $15 \mathrm{mg}$ vials.

\section{In-house recommendations}

As a rule, solutions must be tailored to local requirements while at the same time being financially reasonable. In the given case the $15 \mathrm{mg}$ vials were taken out of stock completely. Alternatively, a different brand with a different label and packaging could have been chosen. If, however, different dosages are required, these could be spread over different wards/units alternatively, and staff awareness should be ensured, either computer based or by bulletins.

\section{Discussion}

About $1 / 3$ of all cases of confusing medication correlate with similar packaging and labeling of drugs, at the same time $50 \%$ of all cases of confusing medication is due to poor performance of qualified staff. Underlying reasons discussed are overly burdened staff and psychological aspects like confirmation bias [2,11-14]. Other problems like translational problems and mistakable labeling errors, which led to errors in the use of implants, were described and discussed in the recent literature [15].

A DRG based health care system payment coerces employees to exert more work in the same given time. This "rat race" leads to more pressure at the bedside, which might favor an increase in errors in medication. An analysis of 235 CIRS case reports within the Department of Anesthesiology showed that an overload of work is the second highest factor contributing to confusing medications as per LASA definition [16]. 


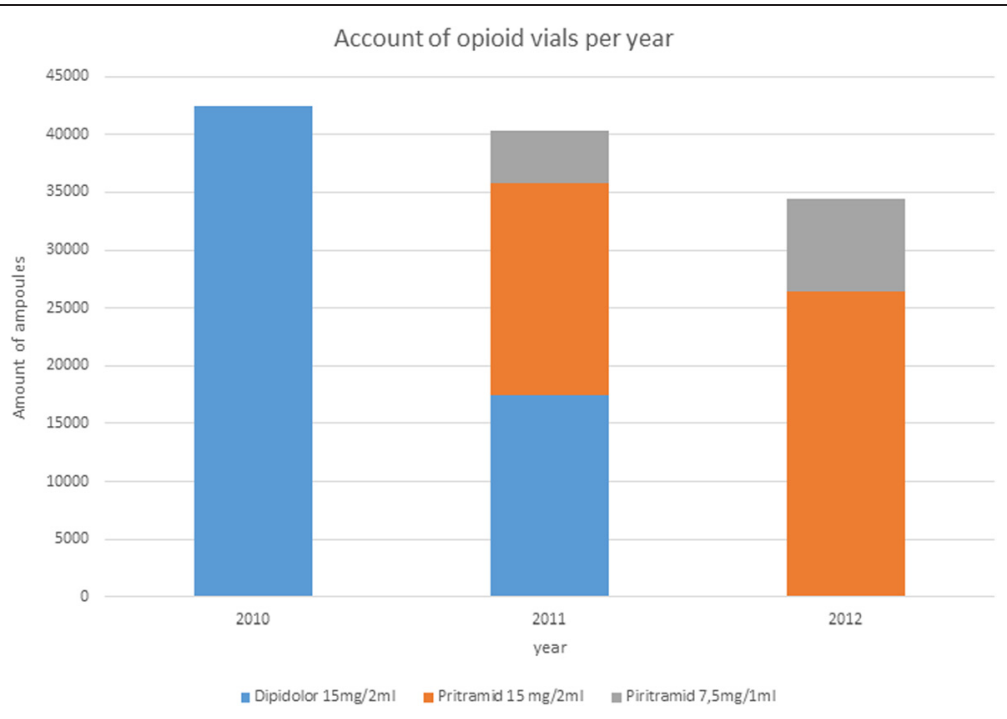

Figure 2 Pharmacy dispensing of Dipidolor ${ }^{\mathrm{Tm}}$ - and Piritramid-vials in 2010-2012.

Sufficient recommendations do exist, targeting practical avoidance of medication errors/LASA. A financial compensation for this is not implemented in the German health care system as per DRG lump sum payment method, despite the fact that both politics as well as insurance companies should feel obliged to do so. Furthermore, pharmaceutical companies could contribute considerably to patient safety by abandoning a corporate design, reducing confusion of medication consecutively.

\section{Conclusion}

Patient safety and cost efficiency do not necessarily have to exclude each other. Still targeting cost efficiency can easily endanger patient safety. Somehow both aspects can be seen as antipodes, where leveling can only be achieved for single cases, just before legal implications come into play.

Every hospital's staff cannot handle the LASA issue individually, but politics as well as pharmaceutical companies can contribute significantly to patient safety regarding medication errors, especially by abandoning corporate design and allowing for a higher variety in packaging and design. Beside the LASA issue, understaffing contributes to confusion of medication and needs to be addressed locally, though determining the right amount of staff versus just not enough seems to be a thin line.

However, adding LASA to this gray area of understaffing and overload of work is an accident waiting to happen. Pressure on implementation of already existing measures to counter LASA experiences a new surge from indemnity insurers, forcing hospitals to invest in their staff and making

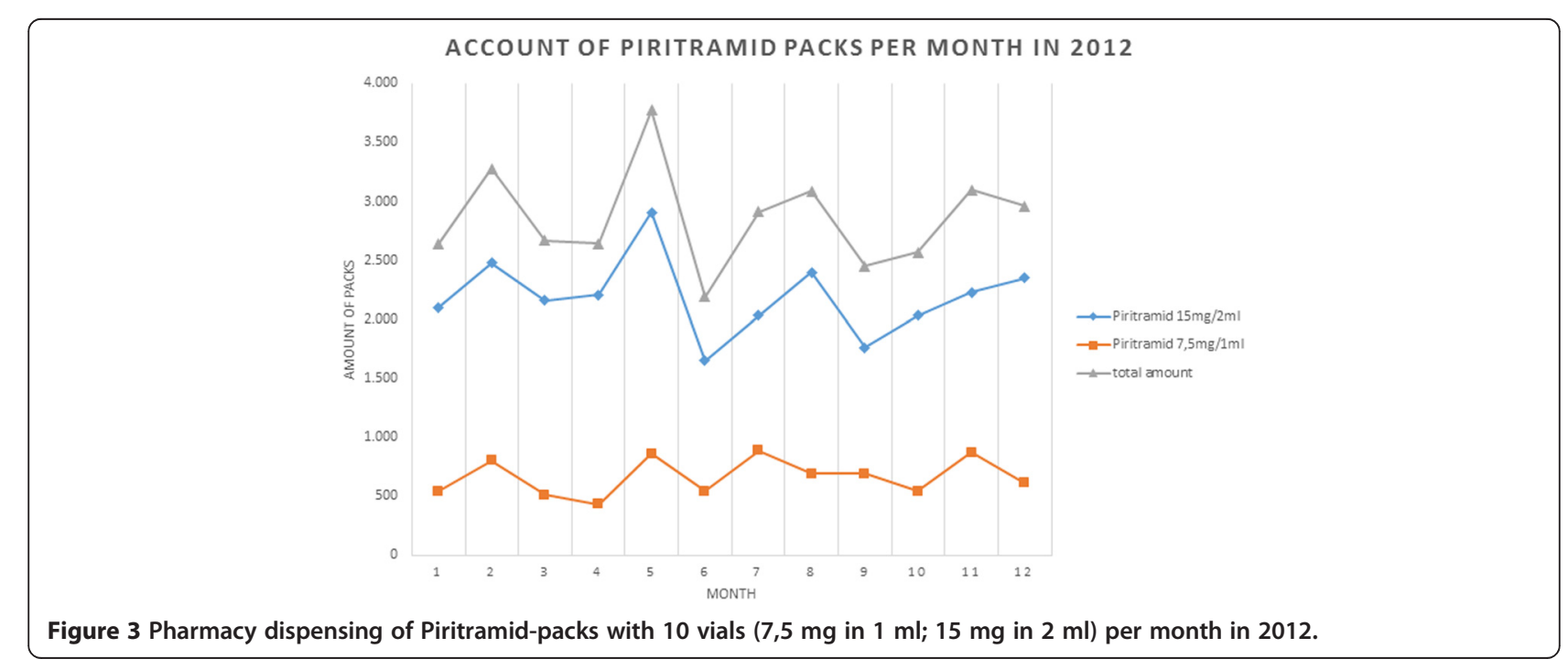


sure that an ever-increasing workload is not detrimental to patient safety, finally leading to health care providers investing in patient safety.

\section{Abbreviations}

DRG: Diagnosis-Related Groups; LASA: Look-alike-sound-alike; CIRS: Critical Incident Reporting System.

\section{Competing interests}

The authors declare that they have no competing interests.

\section{Authors' contributions}

JS conceived the idea for the study, study design and data collection. He performed the data analysis and wrote the manuscript. All co-authors ( $C R, R F, N E$ and $\mathrm{CEH}$ ) contributed to the manuscript. All authors read the manuscript and approved the final version.

\section{Acknowledgements}

We kindly acknowledge support from Heiko Kranz (Executive Nurse for interdisciplinary Endoscopy, Department of Gastroenterology and Rheumatology, University Hospital Leipzig), Andreas Engel and Jan Vogel (Consultants, Pharmacy, University Hospital Leipzig).

\section{Author details}

${ }^{1}$ Department of Anesthesia and Intensive Care Medicine, University Hospital Leipzig, Liebigstraße 20, 04103 Leipzig, Germany. ${ }^{2}$ Office of Quality and Risk Management, University Hospital Leipzig, Liebigstraße 20, 04103 Leipzig, Germany. ${ }^{3}$ Department of Anesthesiology, King's College Hospital Clinics Abu Dhabi LLC, Abu Dhabi, UAE. ${ }^{4}$ Shining Towers, Mubarak bin Mohammed St, Khalidiyah, PO Box 129923, Abu Dhabi, UAE. ${ }^{5}$ Pharmacy, University Hospital Leipzig, Liebigstraße 20, 04103 Leipzig, Germany. ${ }^{6}$ Department of Orthopedics, Traumatolgy and Plastic Surgery, University Hospital Leipzig, Liebigstraße 20, 04103 Leipzig, Germany.

Received: 23 July 2014 Accepted: 9 December 2014

Published online: 13 March 2015

\section{References}

1. Bundesministerium für Gesundheit (BMG): Aktionsplan 2013-2015 zur Verbesserung der Arzneimitteltherapiesicherheit (AMTS) in Deutschland [http://www.akdae.de/AMTS/Aktionsplan/Aktionsplan-AMTS-2013-2015.pdf]

2. Hahnenkamp C, Rohe J, Thomeczek C. Ich sehe was, was du nicht schreibst. Dtsch Arztebl. 2011:108:A1850-4.

3. Schnurrer JU. Medikationsfehler - Ergebnisse des ADKA-Berichtsystems. Krankenhauspharm. 2006:27:477-84.

4. World Health Organization (WHO): Look-Alike, Sound-Alike Medication Names 2007 [http://www.who.int/patientsafety/solutions/patientsafety/PSSolution 1.pdf]

5. Möllemann A, Eberlein-Gonska M, Koch T, Hübler M. Clinical risk management Implementation of an anonymous error registration system in the anesthesia department of a university hospital. Anaesthesist. 2005;54:377-84.

6. Schnoor J, Kranz H, Engel A, Vogel J, Frontini R, Rogalski C: Patient Safety Versus Cost Efficiency? A CIRS Case Study of Scylla and Charybdis. Gesundhökon Qualmanag, in press.

7. Quick Alert Nr 14: Stiftung für Patientensicherheit [http://www.patientensicherheit ch/de/publikationen/Alle-Publikationen-am-Schluss-nicht-sichtbar.html]

8. Poon EG, Keohane CA, Yoon CS, Ditmore M, Bane A, Levtzion-Korach O, et al. Effect of bar-code technology on the safety of medication administration. N Engl J Med. 2010;362:1698-707.

9. Fischer M, Bernard R, Riedel R. Sparen lohnt nicht immer. DtschArztebl. 2013;110:B206-7.

10. Rote Liste 2012. Arzneimittelverzeichnis für Deutschland. Rote Liste ${ }^{\oplus}$ Frankfurt/Main: Service Verlag GmbH; 2012.

11. Berman A. Reducing medication errors through naming, labeling, and packing. J Med Syst. 2004;28:9-29.

12. Hicks RW, Becker SC, Cousins DD. MEDMARX data report. A report on the relationship of drug names and medication errors in response to the institute of Medicine's call for action. Rockville: Center for the Advancement of Patient Safey, US Pharmacopeia; 2008 [http://www.labatecpharma.com/ wp-content/uploads/2012/02/2008MEDMARX-DataReport.pdf]
13. Landrigan CP, Rothschild JM, Cronin JW, Kaushal R, Burdick E, Katz JT, et al. Effect of reducing interns' work hours on serious medical errors in intensive care units. N Engl J Med. 2004;351:1838-48.

14. Valentin A, Capuzzo M, Guidet B, Moreno R, Metnitz B, Bauer P, et al. Errors in administration of parenteral drugs in intensive care units: multinational prospective study. BMJ. 2009;338:b814. doi:10.1136/bmj.b814.

15. Fakler JK, Robinson Y, Heyde CE, John T. Errors in handling and manufacturing of orthopaedic implants: the tip of the iceberg of an unrecognized system problem? Patient Saf Surg. 2007;1(1):5. doi:10.1186/ 1754-9493-1-5.

16. Brinkrolf $P$, Prien $T$, Van Aken H. Medikationsfehler - Eine systematische analyse der Berichte im CIRS-AINS. Anästh Intensiv Med. 2013;54:126-32.

\section{Submit your next manuscript to BioMed Central and take full advantage of:}

- Convenient online submission

- Thorough peer review

- No space constraints or color figure charges

- Immediate publication on acceptance

- Inclusion in PubMed, CAS, Scopus and Google Scholar

- Research which is freely available for redistribution 